\title{
Delayed post-diuretic 18F-FDG PET/CT: can it help in determination of the best clinical decision for muscle invasive UB cancer patients?
}

\author{
Susan Adil Ali ${ }^{* *}$, Moustafa Mahmoud Abdelkawi ${ }^{2}$ and Nervana Magdy Hussien ${ }^{3}$
}

\begin{abstract}
Background: ${ }^{18}$ F-Fluorodeoxyglucose positron emission tomography-computed tomography $\left({ }^{18} \mathrm{~F}\right.$ FDG PET/CT) has been used previously in the staging of the bladder cancer patients. Its main role was to detect regional nodal metastatic spread as well as distant organ metastasis but it was limited in detection of the primary neoplasia and the local tumor recurrence in the urinary bladder due to the presence of excreted radiotracer in the urinary tract, masking the urinary bladder lesion and probably the adjacent small regional metastatic lymph nodes. The aim of this study was to highlight the efficacy of delayed post-diuretic ${ }^{18} \mathrm{~F}$-FDG PET/CT in staging and restaging muscle invasive urinary bladder cancer (MIBC), allowing metabolic evaluation of the primary disease, in addition to detection of associated metastasis which in turn can help to determine the best clinical decision for patients. This prospective study included 35 patients with MIBC, divided into two main groups: group A (18 patients) coming for initial staging and group B (17 patients) coming for post-therapeutic assessment. All patients of both groups were analyzed by a multidisciplinary team and the clinical decisions before and after PET CT were analyzed.
\end{abstract}

\section{Results:}

- In group A, 7/18 patients were upstaged with consequent changing in therapeutic management. No downstaging was reported.

- In group B, the response was reported in 11/17 patients where they proceeded to radical surgery with an excellent agreement to pathological findings. 3/17 patients were stationary and 3/17 patients were progressed.

- PET/CT helped in the determination of the best treatment decision in $68.6 \%$ of patients among both groups.

Conclusion: Delayed post-diuretic PET/CT imaging is an important diagnostic tool in evaluation MIBC patients, which may consequently help to determinate the best clinical decision for them.

\section{Background}

Carcinoma of urinary bladder represents $7 \%$ of all malignancies in males and $2 \%$ of all malignancies in females [1]. Transitional cell carcinoma (TCC) is the most common histologic type of urinary bladder cancer [2]. The most common imaging modalities used for diagnosing bladder cancer are US (ultrasonography), IVU (intravenous urography), CECT (contrast-enhanced computed tomography), and MRI (magnetic resonance imaging). A

\footnotetext{
* Correspondence: dr.susanadil@hotmail.com

${ }^{1}$ Radiodiagnosis Department, Ain Shams University, Cairo, Egypt

Full list of author information is available at the end of the article
}

variable-sized urinary bladder soft tissue mass with frequent infiltration of a vesical wall or extravesical extension is the most common radiological appearance of a primary urinary bladder tumor on these different imaging modalities [3]. Chest and pelviabdominal CECT are the commonest radiological tool for the staging of bladder malignancy. They depict the extravesical extension accurately $[4,5]$. However, both MRI and CECT may overestimate the local disease because their findings are based on changes in the morphologic criteria of the lesion, which may be changed due to an inflammatory response to the tumor or recent biopsies that may not 
correlate with malignancy [6]. ${ }^{18}$ F-Fluorodeoxyglucose positron emission tomography-computed tomography $\left({ }^{18} \mathrm{~F}\right.$ FDG PET/CT) has been used previously in the staging of the patients diagnosed with bladder cancers, but with limited success [7-9]. Its main role was detecting regional nodal metastatic spread, as well as, distant organ metastasis with a 70 and $94 \%$ sensitivity and specificity, respectively [7]. Primary tumor detection and the local tumor recurrence in the urinary bladder are limited due to the presence of excreted radiotracer $\left({ }^{18} \mathrm{~F} F D G\right)$ in the urinary tract, masking the urinary bladder lesion and probably the adjacent small regional metastatic lymph nodes [9]. Possible retrograde irrigation with doublelumen Folly's catheter may be used but was not applicable, due to invasive technique. An alternative method, thus, reducing the urinary bladder radioactivity without alteration of the tumor uptake is needed. Diuretics are the most suitable for this aim, as they are enhancing the elimination of the excreted ${ }^{18} \mathrm{~F}$ FDG by kidneys without interfering with the ${ }^{18} \mathrm{~F}$ FDG uptake in vesical tumor [10-12]. Also, in lesions with high radioactivity backgrounds, such as those in the bladder, may allow differentiation of high-activity bladder lesions from the highly active urine-background [13].

The aim of this study was to highlight the efficacy of delayed ${ }^{18} \mathrm{~F}$ FDG PET/CT in staging and restaging muscle-invasive bladder cancer (MIBC), following administration of diuretics, overcoming the excreted ${ }^{18} \mathrm{~F}$ FDG from the bladder allowing metabolic evaluation of the local primary disease, as well as, detection of the associated nodal and distant metastasis.

\section{Methods}

\section{Patients}

The study was performed from April 2016 till June 2018, included 35 patients who were referred from a clinical oncology unit. Approval of the institutional review board was obtained before the start of this prospective study.

The patients were divided into two major groups. Group A (18 patients), coming for further initial PET/ CT assessment [after conventional diagnostic CECT chest and pelviabdominal studies] before proceeding to radical surgery. Conventional CECT data were including tumor size, site, and extensions, as well as regional/nonregional nodal enlargement [more than $10 \mathrm{~mm}$ ]. Pelvic lymph nodes including the internal and external iliac lymph nodes were considered regional lymphadenopathy [N1 and N2], while common iliac and other LNs above the aortic bifurcation were considered non-regional lymphadenopathy [N3].

Group B patients coming for post-therapeutic follow up where response to treatment was evaluated by comparing pre and post-therapeutic ${ }^{18} \mathrm{~F}$ FDG PET/CT, and clinical decisions were evaluated accordingly.
Pathological findings among the responding patients (11 patients) who proceeded to radical surgery were compared to the post-therapeutic PET/CT clinical findings.

The patient characteristics are detailed in (Table 1). All the patients underwent ${ }^{18} \mathrm{~F}$ FDG PET/CT with postdiuretic delayed images and all studies were performed after written consent from the patients.

\section{${ }^{18} \mathrm{~F}$-FDG PET/CT technique}

All patients were fasting at least $6 \mathrm{~h}$ before the examination. Prior to intravenous injection of ${ }^{18} \mathrm{~F}$-FDG, the blood glucose level was less than $180 \mathrm{mg} / \mathrm{dL} .9-15 \mathrm{mCi}$ of ${ }^{18} \mathrm{~F}$ FDG was injected intravenously. Scanning by a hybrid PET/CT scanner (Philips ${ }^{\circ}$ Ingenuity TF128 multislice computed tomography (CT) scanner, USA) was performed $60 \mathrm{~min}$ after injection. Initial CT acquisition was done without intravenous contrast injection, followed by the PET scan. CT images were taken first, from the head to mid-thigh, using $110 \mathrm{~mA}, 110 \mathrm{kV}, 0.5 \mathrm{~s}$ tube rotation time, $3.3 \mathrm{~mm}$ section thickness (matched PET section thickness). After CT scanning, PET scan covering the same field of view was obtained immediately. The acquisition time was 2 min per table position. PET images were transferred to a workstation to be reconstructed and displayed in axial, coronal and sagittal planes.

\section{Delayed post-diuretic ${ }^{18}$ F-FDG PET/CT imaging protocol}

Immediately after the completion of the acquisition of the whole-body PET/ CT data. All patients were injected with $20 \mathrm{mg}$ of furosemide intravenously, followed by oral hydration by water $(0.8-1 \mathrm{~L})$ and informed to void frequently then hold urine to allow maximum bladder distension. The excretion rate following diuretic is increased, so the washout is rapidly expected, and clearance of urine activity occurs after 30-60 min. Pelvic $\mathrm{PET} / \mathrm{CT}$ images were then acquired using the same parameters as detailed above about $1 \mathrm{~h}$ after diuretic injection.

Table 1 Characteristics and classification of study population

\begin{tabular}{lll}
\hline Age groups & $30-39$ years & $5[14.2 \%]$ \\
& 40-49years & $11[31.4 \%]$ \\
& 50-59years & $16[45.7 \%]$ \\
Sex & 59years & $3[8.5 \%]$ \\
Pathology & Female & $32[91.4 \%]$ \\
& Transitional cell ca. & $3[8.5 \%]$ \\
Groups & Squamous cell ca. & $31[88.5 \%]$ \\
& Group A: initial staging & $4[11.4 \%]$ \\
& Group B: post-therapeutic evaluation & $18[51.4 \%]$ \\
\hline
\end{tabular}




\section{PET/CT images interpretation}

The obtained initial and delayed post-diuretic images were reviewed on a high-resolution computer screen and interpreted by an experienced radiologist and nuclear medicine physician independently. Initial and delayed PET/CT images were reviewed in axial, sagittal, and coronal planes. Any focal areas of abnormal FDG uptake were recorded and measured using maximum standardized uptake value [SUVmax]. In group A, PET/ $\mathrm{CT}$ staging was done compared to diagnostic conventional CT findings of the chest and pelviabdomen [done within 30 days before the PET/CT]. In group B, posttherapeutic PET/CT restaging was done, with comparison of the pre-therapeutic PET/CT findings, for the primary and secondary lesions both morphologically and metabolically.

\section{Statistical analysis}

The collected data was revised, coded, tabulated and introduced to a PC using Statistical package for Social Science ((IBM Corp. Released 2011. IBM SPSS Statistics for Windows, Version 20.0. Armonk, NY: IBM Corp). Kappa statistics to compute the measure of agreement between two investigational methods Kappa's over 0.75 is excellent, 0.40 to 0.75 is fair to good, and below 0.40 is poor.

\section{Results}

In group $\mathrm{A}$, the results of the 18 patients which were presented for their initial diagnosis (Table 2) were as follows:

I. Conventional imaging and FDG PET/CT staging were consistent in 11 patients (61.1\%) which does not change the plan of their treatment.

II. Seven patients (38.9\%) were upstaged as follows:
- Five patients were upstaged to T4b or N1/N2 disease which changed their plan of treatment to systemic treatment before going to radical cystectomy and re-evaluation after 3 months.

- Two patients were upstaged to metastatic disease due to the presence of non-regional metastatic lymph nodes (Fig. 1) or lung/bone metastasis on PET/CT and were not shown in CECT which changed the aim of treatment from curative to palliative intent.

In group $B$, the results of the 17 patients which were presented for post-therapeutic follow-up (Table 3) were as follows: 3 out of 17 patients $(17.65 \%)$ had stationary disease, 11 out of 17 patients (64.7\%) show response after the therapeutic management they received (Fig. 2), and 3 out of 17 patients (17.65\%) show progression of their disease (Fig. 3).

All the responding patients proceeded to radical surgery and pathological staging was compared to post-therapeutic PET/CT staging. There was excellent agreement $(K=0.792)$ between PET/CT findings and pathological findings as regard $\mathrm{N}$ staging, as $75 \%$ of N0 cases by PET/CT had the same staging by pathology, also $100 \%$ of N1 cases by PET/CT were similarily determined by pathology (Table 4 ).

Also, there was excellent agreement $(K=0.838)$ between PET/CT findings and pathological findings as regard $\mathrm{T}$ staging, as $100 \%$ of $\mathrm{T} 2$ and $\mathrm{T} 3$ cases diagnosed by PET/CT had the same staging by pathology; however, none of T4a cases diagnosed by PET/CT were similarly determined by pathology, as $50 \%$ were diagnosed as T3B and $50 \%$ as T4B (Table 5).

So, F18 FDG PET/CT helped in the determination of best treatment decision in $68.6 \%$ of patients among groups $\mathrm{A}$ and $\mathrm{B}$.

Table 2 Clinical tumor staging of group A by conventional CT scan and PET/CT scan at initial staging. Data in numbers (N) and percentages (\%)

\begin{tabular}{|c|c|c|c|}
\hline Variable & & $N$ & $\%$ \\
\hline \multirow[t]{2}{*}{ Tumor stage by conventional CT scan } & Stage II & 4 & 22.2 \\
\hline & Stage IIla & 14 & 77.8 \\
\hline \multirow[t]{5}{*}{ Tumor stage by PET CT scan } & Stage II & 4 & 22.2 \\
\hline & Stage IIla & 7 & 38.9 \\
\hline & Stage IIIb & 5 & 27.8 \\
\hline & Stage IVa & 1 & 5.6 \\
\hline & Stage IVb & 1 & 5.6 \\
\hline \multirow[t]{2}{*}{ Change of tumor stage based on PET CT scan } & Unchanged & 11 & 61.1 \\
\hline & Upstaged & 7 & 38.9 \\
\hline \multirow[t]{3}{*}{ Change in plan based on PET CT scan } & Unchanged & 11 & 61.1 \\
\hline & Changed from radical to systemic treatment for downstaging & 5 & 27.8 \\
\hline & Changed from radical to palliative treatment & 2 & 11.1 \\
\hline
\end{tabular}




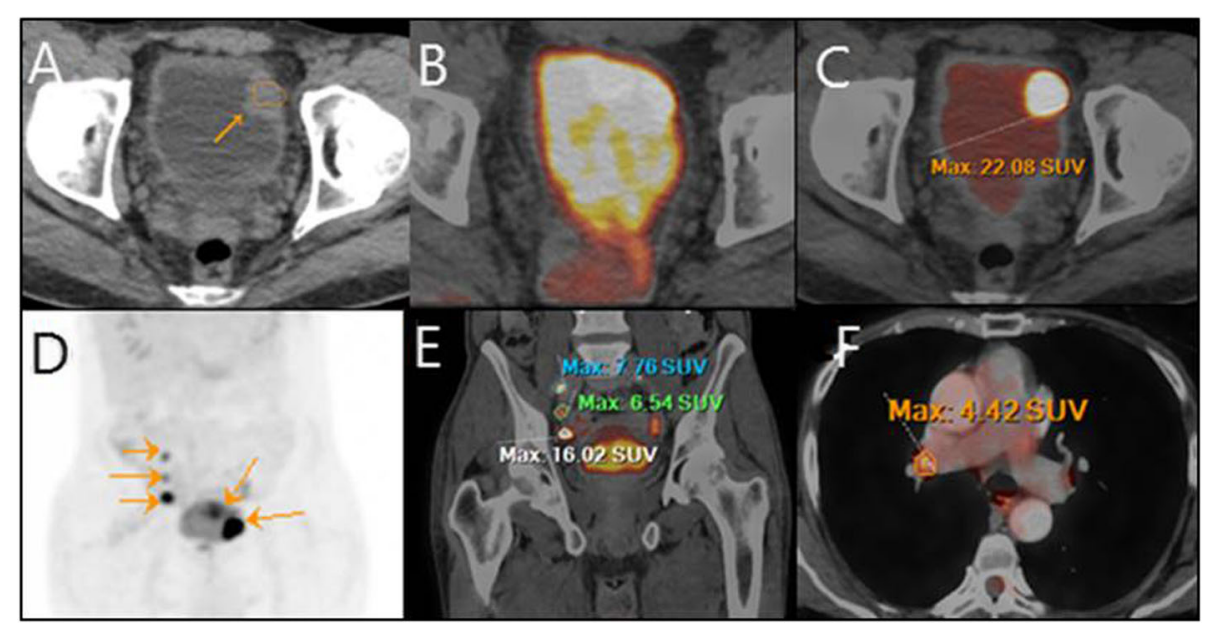

Fig. 1 Fifty-five years old male coming for initial staging of UB mass lesion. a Axial CT images revealed $19.5 \times 20$ mm polypoidal mass lesion with no suspicious LNs in the diagnostic CT done 21 days before the PET CT study. $\mathbf{b}$ Fused PET CT image revealed a total masking of the lesion due to background urine activity. Image $\mathbf{c}$ delayed post-diuretic PET CT revealed clearly differentiated lesion avidity from the surrounding urine activity [SUV max 22.08]. d MIP delayed PET image with increased threshold revealed the bladder lesion and three regional RT external, internal and common iliac LNs confirmed in the fused PET CT pelvic image (e), the largest and most active one measures $15.4 \times 14 \mathrm{~mm}$ seen in the external iliac group achieving 16.02 SUV max. f Fused axial chest PET CT image revealed another small mildly avid right hilar LN achieving 4.4 SUV

\section{Discussion}

Non-invasive imaging is of great value in the staging of MIBC [14]. Many investigators have considered 18FFDG PET is of no value in detecting localized urinary bladder cancers $[15,16]$. This limitation has been predominantly attributed to the urinary excretion of $18 \mathrm{~F}$ FDG. The concentrated activity in the urinary bladder made the mural lesions evaluation difficult [16]. To overcome these limitations of 18F-FDG PET imaging, washing out the excreted 18F-FDG in the urinary bladder is mandatory. Using diuretics before the acquisition, or post-void imaging, or retrograde irrigation of the urinary bladder with a double-lumen Foley catheter, or other tracers were tried by some investigators to improve the sensitivity of PET imaging. A study conducted by Anjos et al. including 17 patients reported that detection of residual or locally recurrent urinary bladder tumors was dramatically improved using ${ }^{18} \mathrm{~F}$ FDG PET/ $\mathrm{CT}$ with delayed imaging following intravenous injection of furosemide as well as oral rehydration [10]. Another similar study conducted by Kamel et al. evaluating the role of forced diuresis in the improvement of diagnostic accuracy of pelviabdominal ${ }^{18} \mathrm{~F}$ FDG PET in 32 patients. Coupling of forced diuresis with parenteral hydration eliminated any significant ${ }^{18} \mathrm{~F}$ FDG activity from the lower urinary tract in 31 of 32 (97\%) patients after voiding the urinary bladder 3 successive times. This study concluded that the furosemide challenge was noninvasively resolved the inherent ${ }^{18} \mathrm{~F}$ FDG contrast handicap in the lower urinary tract [17].

Compared with conventional imaging, several studies found that FDG PET/CT scan has better diagnostic accuracy for the detection of metastatic deposits or other unexpected malignant tumors [18-20]. Nayak et al.

Table 3 Clinical tumor staging of group B by PET CT scan pre- and post-therapeutic. Data are numbers $(N)$ and percentages (\%)

\begin{tabular}{|c|c|c|c|}
\hline Variable & & N & $\%$ \\
\hline Clinical tumor stage before treatment by PET CT scan & Clinical T2-T4a/ N2-N3/M0 & 17 & 100 \\
\hline \multirow[t]{6}{*}{ Clinical tumor stage after treatment by PET CT scan } & Clinical T2/NO/MO & 2 & 11.8 \\
\hline & Clinical T2/N1/Mo & 3 & 17.6 \\
\hline & Clinical T3-T4a/NO-N1/M0 & 6 & 35.3 \\
\hline & Clinical T2-T4a/N2-N3/M0 & 3 & 17.6 \\
\hline & Clinical T4b/N1-3/M0 & 2 & 11.8 \\
\hline & Any T/Any N/M1 & 1 & 5.9 \\
\hline \multirow[t]{3}{*}{ Response of the tumor as assessed by PET/CT pre- and post-treatment } & Response & 11 & 64.7 \\
\hline & Stationary & 3 & 17.6 \\
\hline & Upstaged & 3 & 17.6 \\
\hline
\end{tabular}




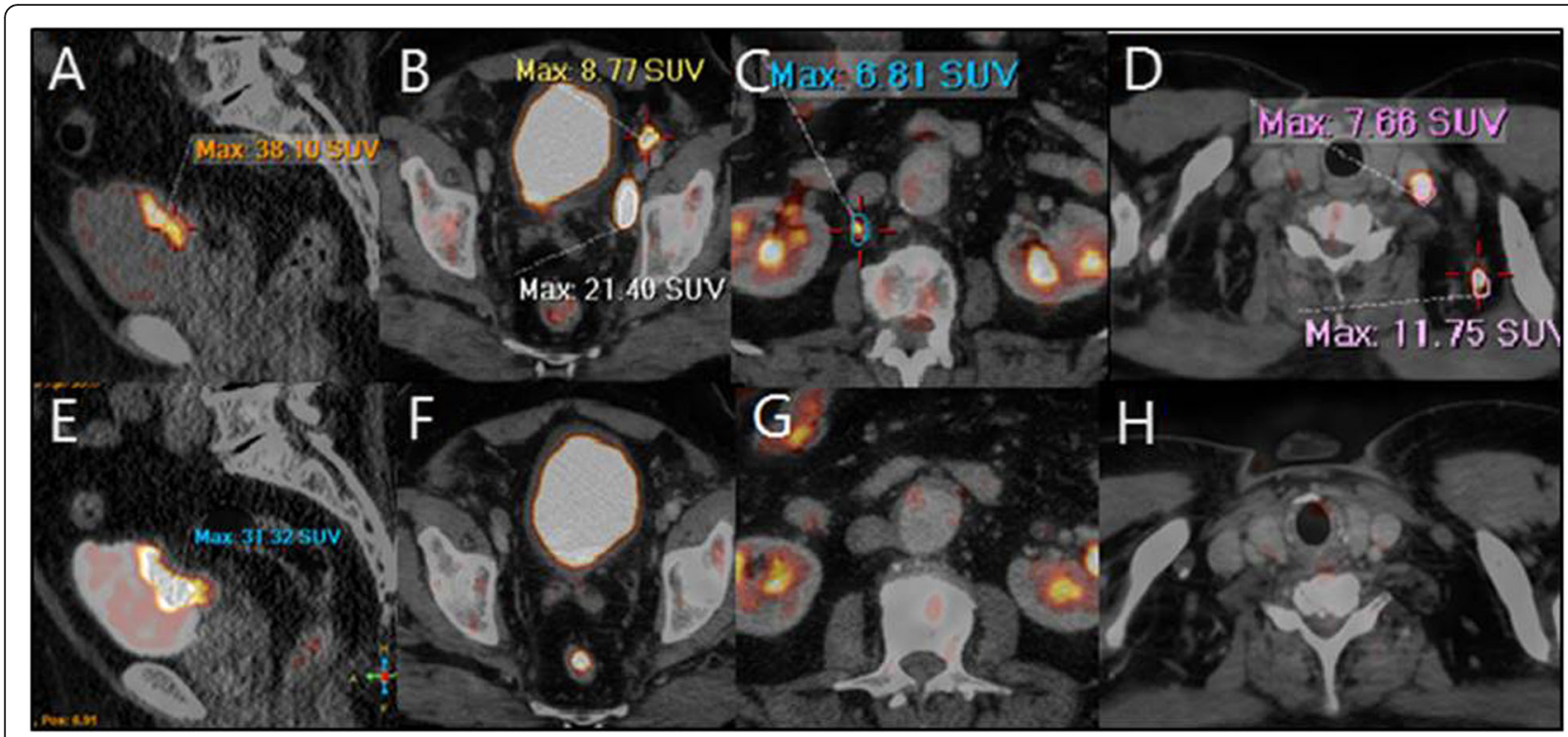

Fig. 2 Seventy years old male patient, presented with pathologically proven undifferentiated metastatic bladder carcinoma. Initial pre-therapeutic delayed PET/CT study revealed (a) primary bladder intensely avid mass lesion, related to the posterosuperior aspect of the UB [SUV max 38.1] with LT external iliac two avid regional LNs (b), posterior triangle/supra clavicular LNs (c), and solitary small sub centimetric retrocaval LN (d). The patient received neoadjuvant chemotherapy and hormonal treatment then coming for follow-up. The post-therapeutic PET/CT revealed (e) partial metabolic response of the primary bladder lesion seen in the delayed post-diuretic PET/CT with metabolic regression from 38.1 to 31.3 SUVmax [with complete metabolic and morphologic resolution of the metastatic regional and distant lymphadenopathies $(\mathbf{f}-\mathbf{h})$

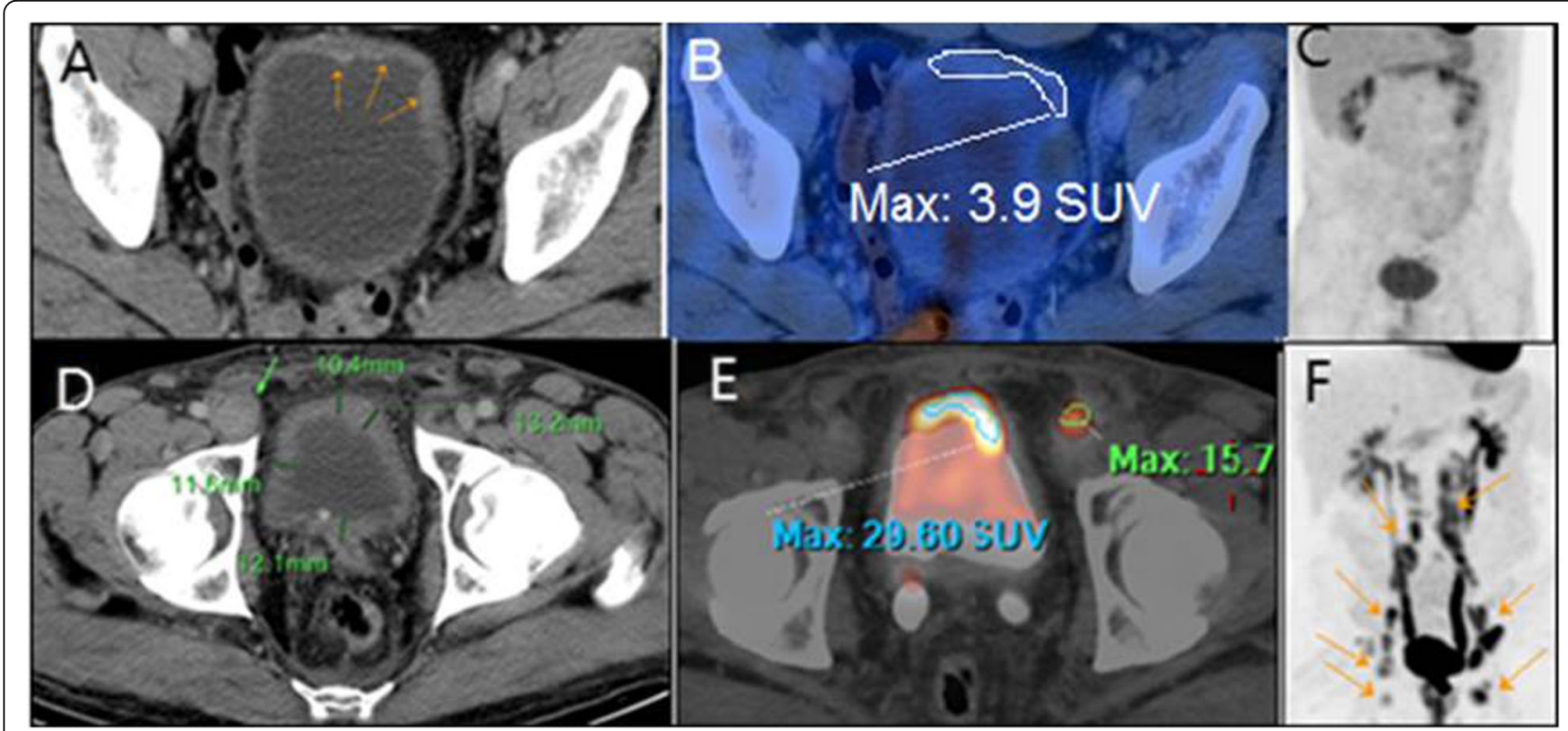

Fig. 3 Forty-five years old patient, having history of hematuria underwent cystoscopy and histopathology revealing transitional cell carcinoma, related to the anterior wall of the UB. a Axial post-contrast CT revealed mild non-uniform mural thickening related to the anterior and left ventrolateral walls of the UB (yellow arrows). $\mathbf{b}$ Corresponding post-diuretic delayed fused PET CT image revealed scanty mural avidity [SUV max 3.9], related to the lesion [over the washed urine background in the bladder lumen]. Three months after regional pelvic irradiation, the bladder had become contracted having circumferential non-uniform mural thickening reaching $13.2 \mathrm{~mm}$ in maximal thickness (d), showing intense ventral and left ventrolateral mural activity [SUV max 29.6] in the corresponding post-diuretic delayed fused PET CT image (e) with development of multiple bilateral iliac and paraaortic as well as right inguinal (green arrow) metastatic hypermetabolic lymphadenopathies (f; yellow arrows). Moreover, the development of mild bilateral back pressure changes and retained tracer in the ureters and collecting systems (f) 
Table 4 Agreement between PET/ CT results and pathology as regard N staging

\begin{tabular}{|c|c|c|c|c|c|c|}
\hline & & \multicolumn{4}{|c|}{ Post-therapeutic PET/CT staging } & \multirow[t]{3}{*}{ Kappa $\left(\mathrm{Cl}^{*}\right)$} \\
\hline & & \multicolumn{2}{|l|}{ No } & \multicolumn{2}{|l|}{ N1 } & \\
\hline & & $N$ & $\%$ & N & $\%$ & \\
\hline \multirow[t]{2}{*}{ Pathological staging after radical surgery } & No & 3 & $75 \%$ & 0 & 0 & $0.792(0.412-1.0)$ \\
\hline & N1 & 1 & $25 \%$ & 7 & 100 & \\
\hline
\end{tabular}

found that CECT and PET/CT studies had a 44 and 78\% sensitivity, respectively in detecting nodal metastasis [21]. Also, a study by Kibel et al. including 43 patients with negative CT as well as, bone scans and PET/CT detected histopathologically proven nodal metastatic infiltrates in 7 out of 9 patients, displaying sensitivity, specificity, positive predictive value, and negative predictive value of $70 \%, 94 \%, 78 \%$, and $91 \%$, respectively [7]. Another review study done by Bouchelouche et al. concluded that ${ }^{18} \mathrm{~F}$ FDG PET/CT was a useful imaging tool in detecting metastatic disease [22].

The present study was carried out to evaluate the importance of delayed post-diuretic FDG PET/CT in initial staging and restaging of 35 patients diagnosed with MIBC and how this was reflected on the treatment decisions of these patients.

In group $\mathrm{A}$, we found a significant difference between FDG PET/CT and conventional imaging staging. Stage migration, due to upstaging by FDG PET/CT occurred in $38.9 \%$ of patients of group A, with major changes in management occurred as a result, both in the selection of treatment method (from direct cystectomy to neoadjuvant chemotherapy for better systemic control) and in overall treatment intent (from curative measurement to palliation), which means that important changes in the therapeutic management and plan of treatment of these patients was done.

In group B, FDG PET/CT helped in good evaluation of patients pre- and post-therapeutic disease (whether stationary course, upstaging, or downstaging of the disease) which helped in proper decision making accordingly.

Other many previous studies have tried to evaluate the impact of FDG PET/CT imaging on the management of patients. A study by Apolo et al. including 57 patients, presented with bladder malignancy revealed that FDG $\mathrm{PET} / \mathrm{CT}$ detected more malignant disease in $40 \%$ of patients than conventional CE-CT or MRI. Questionnaires on intended patient management were completed by oncologists before and after FDG PET/CT to determine how these findings had an effect on patient management. They reported that planned management in $68 \%$ of patients had changed by clinicians based on the FDG PET/CT findings. However, an important limitation of this study was the possibility of disease progression between conventional CECT and FDG PET/CT, since the time interval between them was not determined. Moreover, the method and extent of conventional staging were unclear. Therefore, the results of their analysis may not reflect the true clinical impact of the additional diagnostic data from FDG-PET/CT imaging [8].

Another study by Laura et al. reported that, in 13.5\% of their patients with urinary bladder cancer, the treatment was changed on the basis of FDG PET/CT results (due to FDG PET/CT upstaging), and treatment plan was changed in $4.2 \%$ of patients due to detection of second primary tumors by FDG PET/CT. However, their study was limited by their retrospective design in the form of retrospective assessment of preferred treatment before and after FDG PET/CT which would reflect that the categories used for decision and change in management might be inappropriate and underestimated [23].

A unique feature in the present study is that in group A, the additional diagnostic value of FDG-PET/CT study was compared with conventional imaging that performed within 30 days before FDG PET/CT examination to minimize the possibility of disease progression between the two imaging studies.

Table 5 Agreement between PET/CT results and pathology as regard T staging

\begin{tabular}{|c|c|c|c|c|c|c|c|c|}
\hline & & \multicolumn{6}{|c|}{ PET/CT staging } & \multirow[t]{3}{*}{ Kappa $\left(\mathrm{Cl}{ }^{*}\right)$} \\
\hline & & \multicolumn{2}{|c|}{$\mathrm{T} 2$} & \multicolumn{2}{|l|}{ T3 } & \multicolumn{2}{|c|}{$\mathrm{T} 4 \mathrm{a}$} & \\
\hline & & $N$ & $\%$ & $N$ & $\%$ & $N$ & $\%$ & \\
\hline \multirow[t]{5}{*}{ Pathological staging } & $\mathrm{T} 2$ & 5 & 100.0 & 0 & 0 & 0 & 0 & \multirow[t]{5}{*}{0.838 (0.723 to 0.953$)$} \\
\hline & $\mathrm{T} 3$ & 0 & 0 & 4 & 100.0 & 0 & 0 & \\
\hline & $\mathrm{T} 3 \mathrm{~B}$ & 0 & 0 & 0 & 0 & 1 & 50.0 & \\
\hline & T4a & 0 & 0 & 0 & 0 & 0 & 0 & \\
\hline & $\mathrm{T} 4 \mathrm{~B}$ & 0 & 0 & 0 & 0 & 1 & 50.0 & \\
\hline
\end{tabular}


Post-diuretic FDG PET/CT when was done pre and post-therapy for patients in group B was able to give us a proper evaluation of the primary bladder lesion besides its role in the detection of metastasis in the rest of the body, which helped in proper decision making and accurate therapeutic plan for these patients.

One more advantage over the other studies is that pathological staging for all patients who showed response and proceeded to radical surgery was compared to post-therapeutic clinical staging by PET/CT evaluating its efficacy in the staging of MIBC patients.

Another good feature of the current study is that the 35 patients included in the study were evaluated prospectively within a clear treatment plan according to the most recent guidelines which make the changes in the treatment plans and treatment decisions appropriate and accurate, allowing for true evaluation of the clinical impact of additional diagnostic information from FDG PET/CT.

However, this study is limited by the small number of the included patients and future studies with the larger patient samples are required to assess the efficacy of delayed post-diuretic ${ }^{18} \mathrm{~F}$ FDG PET/CT imaging in the initial diagnosis and follow-up of MIBC patients.

\section{Conclusion}

Post-diuretic delayed ${ }^{18} \mathrm{~F}$ FDG PET/CT imaging is an efficient diagnostic tool in the evaluation of MIBC patients, whether coming for initial staging or restaging following initial therapy, which may consequently affect the therapeutic management of these patients and decrease the possibilities of false decisions.

\section{Abbreviations \\ ${ }^{18}$ F FDG: ${ }^{18}$ F-Fluorodeoxyglucose; CECT: Contrast-enhanced computed tomography; IVU: Intravenous urography; MIBC: Muscle invasive urinary bladder cancer; MRI: Magnetic resonance imaging; PET/CT: Positron emission tomography/ computed tomography; SUV max: Maximum standardized uptake value; TCC: Transitional cell carcinoma; US: Ultrasonography}

\section{Acknowledgements}

Not applicable

\section{Authors' contributions}

MM carried out the PET/CT studies and participated in the design of the study. SA collected the data, participated in the study design, and helped to draft the manuscript. NM performed the statistical analysis and drafted the manuscript. All authors read and approved the final manuscript.

\section{Funding}

This work has not received any funding.

\section{Availability of data and materials}

All data generated or analyzed during this study are included in this article.

\section{Ethics approval and consent to participate}

The study protocol was approved by the Ethical Committee of Helwan University in 2016 (no reference number was given at that time) and written informed consent was obtained from all patients to participate in the study.

\section{Consent for publication}

Written informed consent was obtained from all patients for publication of the study.

\section{Competing interests}

The authors declare that they have no competing interests.

\section{Author details}

${ }^{1}$ Radiodiagnosis Department, Ain Shams University, Cairo, Egypt. ${ }^{2}$ Radiodiagnosis Department, Helwan University, Cairo, Egypt. ${ }^{3}$ Oncology Department, Helwan University, Cairo, Egypt.

Received: 3 December 2019 Accepted: 5 December 2019

Published online: 30 December 2019

\section{References}

1. Jemal A, Murray T, Ward E et al (2005) Cancer statistics. CA Cancer J Clin 55: 10-30

2. Wong-You-Cheong JJ, Woodward PJ, Manning MA, Sesterhenn IA (2006) From the archives of the AFIP: neoplasms of the urinary bladder: radiologicpathologic correlation. Radiographic 26:553-580

3. Kim JK, Park SY, Ahn HJ, Kim CS, Cho KS (2004) Bladder cancer: analysis of multi-detector row helical CT enhancement pattern and accuracy in tumor detection and perivesical staging. Radiology 231(3):725-731

4. Knox MK, Cowan NC, Rivers-Bowerman MD, Turney BW (2008) Evaluation of multidetector computed tomography urography and ultrasonography for diagnosing bladder cancer. Clin Radiol 63(12):1317-1325

5. Husband JE (1995) Computer tomography and magnetic resonance imaging in the evaluation of bladder cancer. J Belge Radiol 78(6):350-355

6. Kim B, Semelka RC, Ascher SM, Chalpin DB, Carroll PR, Hricak H (1994) Bladder tumor staging: comparison of contrast-enhanced CT, T1- and T2weighted MR imaging, dynamic gadolinium-enhanced imaging, and late gadolinium-enhanced imaging. Radiology 193(1):239-245

7. Kibel AS, Dehdashti F, Katz MD, Klim AP, Grubb RL, Humphrey PA et al (2009) Prospective study of [18F] fluorodeoxyglucose positron emission tomography/computed tomography for staging of muscle-invasive bladder carcinoma. J Clin Oncol 27(26):4314-4320

8. Apolo AB, Riches J, Schöder H, Akin O, Trout A, Milowsky Ml et al (2010) Clinical value of fluorine-18 2-fluoro-2-deoxy-D-glucose positron emission tomography/computed tomography in bladder cancer. J Clin Oncol 28(25): 3973-3978

9. DrieskensO OR, VanPoppelH VY, FlamenP ML (2005) FDG-PET for preoperative staging of bladder cancer. Eur J Nucl Med Mol Imaging 32(12): $1412-1417$

10. Anjos DA, Etchebehere ECSC, Ramos CD, Santos AO, Albertotti C, Camargo EE (2007) ${ }^{18}$ F-FDG PET/CT delayed images after diuretic for restaging invasive bladder cancer. J Nucl Med 48(5):764-770

11. Sharma A, Mete UK, Sood A, Kakkar N, Gorla AKR, Mittal BR (2017) Utility of early dynamic and delayed post-diuretic 18F-FDG PET/CT SUVmax in predicting tumour grade and T-stage of urinary bladder carcinoma: results from a prospective single Centre study. Br J Radiol 90:20160787

12. Jiao J, Zou Q, Zhang Y (2018) Effect of diuretic delayed 18F FDG PET CT via oral intake of small dose diuretics in diagnosing urogenital cancers. J Nucl Med 59:1462

13. Chen YK, Yeh CH, Su CT, Tsui CC, Cheng RH, Hung GU, Ka CH (2014) A new method for detecting urinary bladder cancer by using FDG PET/CT. Technology in. Cancer Res Treatment 13(4):369-376

14. Voges GE, Tauschke E, Stöckle M, Alken P, Hohenfellner R (1989) Computerized tomography: an unreliable method for accurate staging of bladder tumors in patients who are candidates for radical cystectomy. J Urol 142(4):972-974

15. Schöder H, Larson SM (2004) Positron emission tomography for prostate, bladder, and renal cancer. SeminNucl Med 34(4):274-292

16. Swinnen G, Maes A, Pottel H, Vanneste A, Billiet I, Lesage K et al (2010) FDG$\mathrm{PET} / \mathrm{CT}$ for the preoperative lymph node staging of invasive bladder cancer. Eur Urol 57(4):641-647

17. Kamel EM, Jichlinski P, Prior JO, Meuwly JY, Delaloye JF, Vaucher $L$ et al (2006) Forced diuresis improves the diagnostic accuracy of ${ }^{18} \mathrm{~F}-\mathrm{FDG}$ PET in abdominopelvic malignancies. J Nucl Med 47(11):1803-1807

18. Ali SA, Abd Elkhalek YI (2016) Value of integrated PET/CT in detection of hepatic metastatic deposits. EJRNM 47(2):459-465 
19. Ali SA, Abd Elkhalek YI (2016) Added value of combined 18F-FDG PET/ CT for detection of osseous metastases in cancer patients. EJRNM 47(2): 453-458

20. Ali SA, Hamed MA (2017) The diagnostic efficacy of whole body 18F-FDG PET CT in detection of unexpected second primary malignancy in cancer patients. EJRNM 48(3):671-676

21. NayakB Dogra PN, Naswa N, Kumar R (2013) Diuretic ${ }^{18}$ F-FDG PET/CT imaging for detection and locoregional staging of urinary bladder cancer: prospective evaluation of a novel technique. Eur J Nucl Med Mol Imaging 40:386-393

22. Bouchelouche K, Turkbey B, Choyke PL (2012; Suppl) PET/CT and MRI in Bladder Cancer. J Cancer Sci Ther 14(1). https://doi.org/10.4172/1948-5956. S14-001

23. Mertens LS, Fiolle-Bruining A et al (2013) Impact of ${ }^{18}$ F-fluorodeoxyglucose (FDG) positron emission tomography/computed tomography (PET CT) on management of patients withcarcinoma invading bladder muscle. BJU Int 112:729-734

\section{Publisher's Note}

Springer Nature remains neutral with regard to jurisdictional claims in published maps and institutional affiliations.

\section{Submit your manuscript to a SpringerOpen ${ }^{\circ}$ journal and benefit from:}

- Convenient online submission

- Rigorous peer review

- Open access: articles freely available online

High visibility within the field

- Retaining the copyright to your article

Submit your next manuscript at $\boldsymbol{\nabla}$ springeropen.com 